\title{
Implementation of clinical pharmacy service in a tertiary psychiatric hospital in Aseer region, Saudi Arabia: 15 month experience.
}

\author{
Alshahrani SM*, Abosamra SM, Khobrani M \\ Department of Clinical Pharmacy, College of Pharmacy, King Khalid University, Abha, Saudi Arabia
}

\begin{abstract}
Background: The provision of clinical pharmacy related services involves not only medication therapy, but decisions about medication selection, dosages, routes and methods of administration, medication therapy monitoring, and the provision of medication-related information and counselling to individual patients.

Objective: To evaluate the clinical pharmacist's interventions with a focus on resolving drug related problems (DRPs).

Methods: This is a prospective study that was performed in a tertiary mental health hospital in Abha city, Saudi Arabia. The clinical pharmacy team conducted a clinical rotation on a daily basis for rendering clinical pharmacy services. Based on the clinical pharmacist's assessment, the identified DRP's were identified and communicated with other clinicians to concerned patient-centered care and the resulting outcomes were measured. Also, the acceptance rate for the clinical pharmacist's interventions was evaluated.

Results: A total of 824 DRPs were identified for 420 cases. The most common DRPs reported were found to be regarding Therapeutic Drug Monitoring $(n=345,41.87 \%)$ followed by need for counselling $(n=175$, $21.24 \%)$, drug selection $(n=180,21.84 \%)$, over or under dosage $(n=87,10.6 \%)$, adverse reactions $(n=20$, $2.43 \%)$, compliance $(n=14,1.7 \%)$, and under treatment $(n=3,0.36 \%)$. For all the identified DRP's a total of 446 interventions $(54.13 \%)$ were proposed and accepted by the clinicians.

Conclusion: Present study showed that introducing clinical pharmacist within the psychiatry team improves the therapeutic optimization and the clinical pharmacist is a trustworthy team member.
\end{abstract}

Keywords: Clinical Pharmacy, Tertiary, Psychiatric, Drug Related Problem, Intervention.

Accepted on July 23, 2019

\section{Introduction}

Psychiatry practice is a multidisciplinary field that requires different disciplines to work in collaboration towards achieving optimal patient-centered care [1]. Neuropsychiatric medications, offer variety of challenges to clinicians because of the enormous potential of drug-drug interactions, therapeutic drug monitoring requirements, and mistreatment possibilities [2]. Therefore, practicing neuropsychiatry demands welltrained clinicians to provide the optimal therapeutic interventions and clinical decisions to manage the diseases and the problems arising from the use of drug therapy [2-4].

Pharmacists contribute in assessment of patient past and present medication history, laboratory work-up, exam findings, and planning for therapeutic treatment goals. During the daily routine rounds, clinical pharmacists look after their patients with collaboration with psychiatrists, social workers, and other health care team members through finding and correcting drug related problems (DRPs) [5-7]. Furthermore, pharmacists in neuropsychiatric practice participate in resolving DRP and reduce medication appropriateness index (MAI) that lead to improve patient safety [8]. Moreover, pharmacists will help to avoid serious side effect of neuropsychiatric medications [8]. In addition, appropriate solving of DRPs will lead to decrease the cost and shorten the patient's length of stay [6,8-10].

From the literatures, the acceptance rate of clinical pharmacist's interventions within psychiatric team showed optimism among clinicians where it was equal or more than $70 \%$ from either clinical pharmacists or clinical pharmacy residents $[11,12]$.

In Saudi Arabia, the prevalence of mental disorders was found to be about $35 \%$ among primary health care centers (PHC) visitors while depression was found in different study to occur in $20 \%$ of PHC patients $[13,14]$.

The concept of clinical pharmacy was first introduced into Saudi Arabia in King Faisal Hospital and Research Center (KFHRC) at Riyadh in 1970s. Since then, the clinical pharmacy services have grown to include ministry of defense, ministry of national guard, and ministry of health hospitals around the country [15]. However, in the Southern region (Aseer Province), the clinical pharmacy service firstly 
introduced into ministry of health hospitals in early 2016. To our knowledge, there is no previous study conducted in Saudi Arabia discussing the impact of clinical pharmacist within psychiatric hospital on DRPs interventions.

The goal of this study is to assess the impact of having a clinical pharmacist within psychiatric team in a tertiary mental health hospital. The study aims to evaluate the clinical pharmacist interventions with a focus on resolving DRPs and to assess how the acceptance rate towards the clinical pharmacist interventions improve over time.

\section{Methods}

\section{Clinical setting}

The study was conducted at a tertiary Mental Health Hospital (MHH) in Abha city which is the largest mental tertiary hospital (equipped with more than 100 beds) in the southern region of Saudi Arabia. It provides health care for population of Aseer, Jizan, and Najran provinces and many rural cities.

\section{Study design and duration}

The clinical pharmacy team at Mental Health Hospital, was delegated from King Khalid University, Pharmacy college since October 2016, to assists the medical team by reviewing the paper-based medical records and identify and resolve any DRPs then provide clinical advices regarding drugs during the day-to-day clinical rounds and answering patient-drug related questions, providing medication education for the staff and patients, and training PharmD interns.

This is a descriptive study for evaluation of DRPs that were identified by the clinical pharmacist and the response rate of other clinical team members toward the clinical pharmacist's interventions. The study was carried out for a period of 15 months from October 2017 to December 2018.

\section{Data collection}

The hospital was visited by the clinical pharmacy team on daily basis for rendering clinical pharmacy services and proposing interventions including dosing patients counselling, recommendations, therapeutic monitoring, Drug related problems, Drug-drug interaction reporting and medication adherence. Further assessment and evaluation was made by collecting patient specific data including patient's demographic information, vital signs, baseline lab investigations and medications including drug name, dose, frequency, administration and TDM levels. Based on the assessment and evaluation of patient specific drug related needs and problems necessary interventions/recommendations were proposed to the medical team. The categories of interventions were assumed mainly as per major DRPs and during the daily routine round, the clinical pharmacist was emphasizing and discussing these interventions with the clinical team. By the end of each rotation period, all results were discussed within the clinical pharmacy department meeting (clinical pharmacy preceptors and interns) as end-of-rotation evaluation.

\section{Statistical analysis}

Data was analyzed using SPSS version 22. The descriptive analysis was performed using mean and standard deviation (SD) for continuous variables and percentage for qualitative variables.

\section{Results}

A total of 824 DRPs were identified for 420 cases which is the total number of patients during the period between October 2017 and December 2018. The most common DRPs reported were therapeutic drug monitoring (TDM) for neuropsychiatric medications $(n=345,41.87 \%)$ followed by interventions that required educational effort for residents, interns, and nurses $(\mathrm{n}=175,21.24 \%)$, drug selection problems including duplication, drug interactions, wrong drug selection, and inappropriate dosage form $(n=180,21.84 \%)$, over or under dosage $(n=87,10.6 \%)$, toxicity or adverse reactions $(n=20$, $2.43 \%$ ), compliance including nursing medication errors and discrepancies between orders $(n=14,1.7 \%)$, and finally under treatment $(n=3,0.36 \%)$.

The categories of DRPs and example of interventions after 15month clinical pharmacy service implementation is presented in Table 1. Examples of the interventions made by the clinical pharmacist are shown in Tables 2 and 3. The average response rate was calculated based on the interventions that have been accepted by the medical team to implement. The response rate showed a gradual improvement during the period of study Figure 1. However, a total of 446 interventions (54.13\%) were acknowledged and positively accepted by the clinicians by the end of 12th rotation. The total number of rejected interventions was $378(45.87 \%)$ Table 4 . Most of rejected interventions did not seem to affect the patients' health or therapeutic regimen. The clinicians were still in need for more educational sessions especially medical interns and staff physicians.

\section{Discussion}

The role of clinical pharmacist within the different medical team was evaluated in developing countries. The cornerstone in the clinical pharmacy services within multidisciplinary medical team is to provide the required training and residency programs within the hospitals [16,17]. The clinical pharmacy service is still evolving and expanding in Saudi Arabia to cover all five regions (Southern, Northern, Western, Eastern, and the Middle region) and different ministries' hospitals (Ministry of health, National Guard Hospitals, Armed Force Hospital, and King Faisal Specialist Hospitals). The clinical pharmacy presence in many clinical settings was well established and developed especially in pediatric ICU, Adult ICU, Hematology/Oncology etc at many hospitals in Saudi Arabia [18]. According to the Board of Pharmacy Specialists in Saudi Arabia, there is 543 board-certified pharmacists in Saudi Arabia by 2018 [19]. To our knowledge, this is the first study that evaluated the role of clinical pharmacists in the psychiatry area in Saudi Arabia. 
In this study, we found that the implementation of clinical pharmacy service within the psychiatric medical team helped to identify drug selection related problems in $21.84 \%$ of the total DRPs evaluated. Most of the drug-selection related problems come from the duplication, drug interaction, wrong drug selection etc., where the toxicity or adverse drug reactions were observed 20 times (2.43\%), the majority of DRPs resulted from monitoring of psychiatric medications (TDM) 41.87\%, and patients and staff education (21.24\%) Table 2. Psychiatric medications in comparison to other medications are considered as a major source of medication errors and required close attention for their pharmacokinetic (TDM) and pharmacodynamics (signs of adverse reactions) parameters $[9,20,21]$.

These findings are similar to what was found in previous studies whereas the most common interventions by the clinical pharmacist were originated from providing drug monitoring (baseline assessment and treatment follow-up), treatment recommendations, and patient education [22-24]. Moreover, the medication errors resulted from omission were the most common errors among psychiatric patients boarded in emergency department [25].

Table 1. Clinical pharmacist's interventions (Major categories).

\begin{tabular}{|c|c|c|}
\hline Clinical pharmacist interventions & Psychiatry & \\
\hline Drug-related Problem (DRP) & Number $(\mathrm{N})$ & Percentage \\
\hline \multicolumn{3}{|l|}{ Drug selection } \\
\hline $\begin{array}{l}\text { (Duplication, Drug interaction, Wrong drug, Inappropriate dosage form, Contraindications apparent, No indication } \\
\text { apparent, Other drug selection problem) }\end{array}$ & 180 & $21.84 \%$ \\
\hline $\begin{array}{l}\text { Over or underdoes prescribed } \\
\text { (Prescribed dose too high, Prescribed dose too low, Incorrect or unclear dosing instructions, Other dose problem) }\end{array}$ & 87 & $10.60 \%$ \\
\hline $\begin{array}{l}\text { Compliance } \\
\text { (nursing medication error, discrepancy between orders) }\end{array}$ & 14 & $1.70 \%$ \\
\hline $\begin{array}{l}\text { Undertreated } \\
\text { (Condition undertreated, Condition untreated, Preventive therapy required, Other untreated indication problem) }\end{array}$ & 3 & $0.36 \%$ \\
\hline $\begin{array}{l}\text { Monitoring } \\
\text { (Laboratory monitoring, Non-laboratory monitoring, Other monitoring problem) }\end{array}$ & 345 & $41.87 \%$ \\
\hline $\begin{array}{l}\text { Education and information } \\
\text { (patient, physician or nurse requests drug information, patient, physician or nurse requests disease management } \\
\text { advice, Other education or information problem) }\end{array}$ & 175 & $21.24 \%$ \\
\hline $\begin{array}{l}\text { Toxicity or adverse reaction } \\
\text { (Toxicity, allergic reaction or adverse effect present) }\end{array}$ & 20 & $2.43 \%$ \\
\hline Total & 824 & $100 \%$ \\
\hline
\end{tabular}

Table 2. Examples of clinical pharmacist's interventions in psychiatric area.

\begin{tabular}{|c|c|c|c|}
\hline Classification of the intervention & Case description & Clinical pharmacist intervention & Outcome \\
\hline Education (patient and staff) & $\begin{array}{l}\text { Nurse needed to administer Risperidone } \\
25 \mathrm{mg} \text { IM long-acting injection }\end{array}$ & $\begin{array}{l}\text { For Risperidone IM preparations, } \\
\text { double gloves, a protective gown and } \\
\text { ventilated engineering controls are } \\
\text { recommended }\end{array}$ & $\begin{array}{l}\text { Clear instructions to the nurse } \\
\text { and the result was positive }\end{array}$ \\
\hline Therapeutic Drug Monitoring (TDM) & $\begin{array}{l}\text { Patient started on Lithium } 300 \mathrm{mg} \text { twice } \\
\text { daily orally for Bipolar mania }\end{array}$ & $\begin{array}{l}\text { Levels should be withdrawn twice } \\
\text { weekly until patient's clinical status and } \\
\text { levels are stable (trough level after } 5 \\
\text { days from drug starting) }\end{array}$ & $\begin{array}{l}\text { Clear instructions to the } \\
\text { physician and the result was } \\
\text { positive }\end{array}$ \\
\hline
\end{tabular}

In this study, the overall prescriber's response rate for the clinical pharmacist's interventions has shown an improvement in accepted interventions from $18 \%$ to $54.13 \%$ at the last 12 th rotation. However, the acceptance rate was gradually improved over time to reach to acheive $71.66 \%$ as an average of the last three rotations (Figure 1). This result indicated that the medical team rejection to the clinical pharmacist interventions has to be taken as a tool to improve educational and communication skills of clinical pharmacist and their interns. However, these results go well with the results from Hannou et al. when they used two different techniques (STOP/START) where the total acceptance rate for clinical pharmacist's interventions was 
$44 \%$ and $58 \%$ for STOP and START techniques respectively

[12].

Table 3. Acceptance rate of clinical pharmacist's interventions in psychiatric area.

\begin{tabular}{|c|c|c|c|}
\hline Classification of the intervention & Case description & Clinical pharmacist intervention & Outcome \\
\hline Drug selection & $\begin{array}{l}\text { Patient became in resistant stage of } \\
\text { schizophrenia with suicidal symptoms } \\
\text { appeared and the physician started } \\
\text { combination therapy of Olanzapine and } \\
\text { Valproic acid }\end{array}$ & $\begin{array}{l}\text { Clozapine monotherapy should be started } \\
\text { for patients with resistant schizophrenia } \\
\text { especially in suicidal symptoms }\end{array}$ & $\begin{array}{l}\text { Clear instructions to the } \\
\text { physician and the result was } \\
\text { positive }\end{array}$ \\
\hline Over and under - dose prescription & $\begin{array}{l}65 \text { years old patient was on Citalopram } 40 \\
\text { mg daily per oral for Major depressive } \\
\text { disorder }\end{array}$ & $\begin{array}{l}\text { For patients are more than } 60 \text { years of age, } \\
\text { the maximum recommended dose of } \\
\text { Citalopram is } 20 \mathrm{mg} / \text { day due to the risk of } \\
\text { QTc prolongation }\end{array}$ & $\begin{array}{l}\text { Clear instructions to the } \\
\text { physician and the result was } \\
\text { positive }\end{array}$ \\
\hline
\end{tabular}

Table 4. Clinical pharmacist's intervention acceptance rate as per clinical rotations.

\begin{tabular}{llcc}
\hline $\begin{array}{l}\text { Prescriber } \\
\text { Response }\end{array}$ & $\begin{array}{l}\text { Number of accepted or } \\
\text { interventions }\end{array}$ & rejected & Percentage \\
\hline Accepted & 446 & $54.13 \%$ \\
\hline Rejected & 378 & $45.87 \%$ \\
\hline Total & 824 & $100 \%$ \\
\hline
\end{tabular}

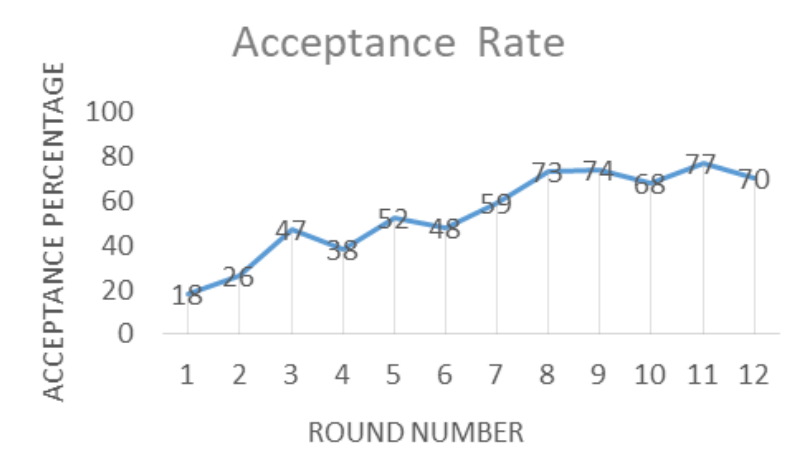

Figure 1. Line graph indicating the gradual improvement in acceptance rate over 12 rounds.

In the other hand, our improvement in response results will be comparable with the expectations of psychiatrists in Saudi Arabia toward clinical pharmacists when it has shown that $70 \%$ of psychiatrists see the clinical pharmacist as a reliable source of drug in neuropsychiatric field [26].

\section{Conclusion}

The implementation of clinical pharmacy service in a tertiary psychiatric hospital showed the requirement for comprehensive patient-medication profile by a drug expert to maximize the patient-care outcomes. The positive impact of clinical pharmacist interventions on psychiatric patients reflected by appropriate drug selection, patients and medical staff education, and therapeutic drug monitoring. From our results, the clinical pharmacy service is crucial to utilize the benefit of drug therapy management at health-care system and psychiatric institutions in particular.

\section{Acknowledgement}

The authors would like to thank King Khalid University for the administrative support to perform this research.

\section{Conflict of Interest}

The authors declare that there is no conflict of interest of any kind regarding execution of this paper.

\section{Funding}

This paper hasn't received any financial funding from any agency nationally or internationally.

\section{References}

1. Alderman CP, Lucca JM. Psychiatry and clinical pharmacy: A logical partnership. Indian J Psychiatry 2017; 59: 138-40

2. Mental disorders. World Health Organization 2016.

3. Stein, Dan J. "What is a mental disorder? A perspective from cognitive-affective science". Canadian Journal of Psychiatry 2016; 58: 656-62.

4. Rubio-Valera M, Chen TF, O'Reilly CL. New roles for pharmacists in Community Mental Health Care: A narrative review. International Journal of Environmental Research and Public Health 2014; 11: 10967-10990.

5. Alderman CP. A prospective analysis of clinical pharmacy interventions on an acute psychiatric inpatient unit. J Clin Pharm Ther 1997; 22: 27-31.

6. Mishra A, Gudi SK, Sravani A, Kurian TD, Kurian J, Ramesh M, rao KM. Impact of pharmacist-led collaborative patient education on medication adherence and quality of life of schizophrenia patients in a tertiary care setting. Bulletin of Faculty of Pharmacy, Cairo University 2017; 55: 345-349.

7. Comprehensive Medication Management (CMM) Guide. CPNP 2017.

8. Wolf C, Pauly A, Mayr A, Grömer T, Lenz B, Kornhuber J, Friedland K. Pharmacist-Led Medication Reviews to Identify and Collaboratively Resolve Drug-Related Problems in Psychiatry: A Controlled, Clinical Trial. PLoS ONE. 2015; 10: 11. 


\section{month experience}

9. Rothschild JM, Mann K, Keohane CA, Williams DH, Foskett C, Rosen SL, Flaherty L, Chu JA, Bates DW. Medication safety in a psychiatric hospital. Gen Hosp Psychiatry 2007; 29: 156-62.

10. American Psychiatric Association Task Force on Patient Safety. Patient safety and psychiatry. Recommendations to the APA Board of Trustees Association 2003.

11. Gardner KN, Diefenderfer LA, Nelson LA, Iuppa C, Elliott E, Kleinhesselink K, Sass D, Sommi RW. Cost-avoidance and qualitative analysis of clinical pharmacy interventions by psychiatric pharmacy residents at state psychiatric facilities. Am J Health Syst Pharm 2016; 73: 1.

12. Hannou S, Voirol P, Pannatier A, Weibel ML, Sadeghipour F, von Gunten A, Mall JF, De Giorgi Salamun I. Pharmacist intervention acceptance for the reduction of potentially inappropriate drug prescribing in acute psychiatry. Int $\mathrm{J}$ Clin Pharm 2017; 39: 1228.

13. Becker S, Al Zaid K, Al Faris E. Screening for Somatization and Depression in Saudi Arabia: A Validation Study of the PHQ in Primary Care. Int J Psychiatry Med 2002; 32: 271-283.

14. Alghadeer SM, Alhossan AM, Al-Arifi MN, Alrabiah ZS, Ali SW, Babelghaith SD, Altamimi MA. Prevalence of mental disorders among patients attending primary health care centers in the capital of Saudi Arabia. Neurosciences (Riyadh) 2018; 23: 239-243.

15. Fathelrahman A, Ibrahim M, Wertheimer A. Pharmacy practice in Saudi Arabia. In: Pharmacy practice in developing countries: achievements and challenges. New York (NY). Academic Press 2016; 172-95.

16. Ghayur MN. Pharmacy education in developing countries: need for a change. Am J Pharm Educ 2008; 72: 94.

17. Parthasarathi G, Ramesh M, Nyfort-Hansen K, Nagavi BG. Clinical Pharmacy in a South Indian Teaching Hospital. Annals of Pharmacotherapy 2002; 36: 927-32.

18. Al-jedai A, Qaisi S, Al-meman A. Pharmacy practice and the health care system in Saudi Arabia. Can J Hosp Pharm 2016; 69: 231-237.
19. Board of Pharmacy Specialties Washington (DC). The Board 2019.

20. Bates DW, Cullen DJ, Laird N, Petersen LA, Small SD, Servi D, Laffel G, Sweitzer BJ, Shea BF, Hallisey R. Incidence of adverse drug events and potential adverse drug events: Implications for prevention. JAMA 1995; 274:2934.

21. Grasso B. Medication errors in psychiatric care: J Pharm Financ Econ Policy 2007; 15: 73-108.

22. Finley PR, Crismon L, Rush AJ. Evaluating the impact of pharmacists in mental health: a systematic review. Pharmacotherapy 2003; 23: 1634-1644.

23. Canales PL, Dorson PG, Crismon ML. Outcomes assessment of clinical pharmacy services in a psychiatric inpatient setting. Am J Health-Syst Pharmacy 2001; 58: 1309-16.

24. Finley PR, Rens HR, Pont JT, Gess SL, Louie C, Bull SA, Lee JY, Bero LA. Impact of a collaborativecare model on depression in a primary care setting: a randomized controlled trial. Pharmacotherapy 2003; 23: 1175-85.

25. Bakhsh HT, Perona SJ, Shields WA, Salek S, Sanders AB, Patanwala AE. Medication errors in psychiatric patients boarded in the emergency department. Int J Risk Saf Med 2014; 26: 191-198.

26. Al-Aqeel S, Al-Sabhan J, Al-Jumah K. A survey of psychiatrists' expectations of clinical pharmacists in Riyadh, Saudi Arabia. Med Princ Pract 2012; 21: 383-388.

\section{*Correspondence to}

Alshahrani SM

Department of Clinical Pharmacy

College of Pharmacy, King Khalid University

Abha

Saudi Arabia 